\title{
EAl Endorsed Transactions

\section{Systematic Review of Utilized ICTs in Quality Assurance and Accreditation of Higher Education and a Case Study of Developing Country}

\author{
A.S. Haris ${ }^{1, *}$, H. Washizaki ${ }^{1}$ and Y. Fukazawa ${ }^{1}$ \\ ${ }^{1}$ Waseda University, Tokyo Japan
}

\section{Abstract}

Numerous studies and surveys have examined the utilization of Information and Communication Technologies (ICTs) in Higher Education (HE), but the lack of studies on the utilization of ICTs in Quality Assurance and Accreditation (QAA) of HE led us to perform a Systematic Literature Review (SLR). This review mainly benefits QAA agencies and researchers interested in utilizing ICTs for QAA of HE. Several contributions of ICTs to QAA of HE are identified. 1) Compared to QAA agencies, Higher Education Institutions (HEIs) are more likely to implement ICTs. 2) Most ICTs in HEIs are for Quality Assurance (QA). 3) Most previous studies were conducted in Europe, demonstrating that efforts have been made to align QAA agencies and HEI QAA units with European Standards. Consequently, ICTs are more often utilized by European HEIs. Furthermore, we investigated the QAA status in a developing country (Afghanistan) as a case study.

Keywords: Systematic Literature Review, ICT, Quality Assurance, Accreditation, Higher Education, Afghanistan.

Received on 02 June 2018, accepted on 11 October 2018, published on 30 October 2018

Copyright (C) 2018 A.S. Haris et al., licensed to EAI. This is an open access article distributed under the terms of the Creative Commons Attribution licence (http://creativecommons.org/licenses/by/3.0/), which permits unlimited use, distribution and reproduction in any medium so long as the original work is properly cited.

doi: 10.4108/eai.13-7-2018.156639

"Corresponding author. Email:ali.chum7@gmail.com

\section{Introduction}

Higher Education (HE) plays a significant role in producing professionals and experts in diverse fields. On the one hand, it is a globally accepted that highly educated individuals are more likely to be highly active in the educational system itself or the labour market [1]. On the other hand, evolution is a natural part of human society. Thus, the benefits of a static educational system have not been as widely accepted by fast-developing markets and societies. Consequently, governments, independent educational organizations, and universities have established practical steps toward assessment of their educational services by focusing on quality. Although the definition and attributes of quality differ based on circumstances and perspectives, this aspect is beyond the scope of this study.
This study uses the definition of some key terms according to United Nations Educational Scientific and Cultural Organization (UNESCO) [2], and we used the definition of SLR according to Kitchenham [3]. Some key terms and their definitions include:

- Quality Assurance (QA) is an "all-embracing term referring to an ongoing and continuous evaluation process (assessing, monitoring, guaranteeing, maintaining, and improving) of the quality of the higher education system, institutions, or programs." [2] (p. 74).

- Accreditation is "the process by which a (non)governmental or private body evaluates the quality of a higher education institution as a whole or a specific educational program to formally recognize it as having met predetermined minimal criteria or standards." [2] (p. 24). 
- Assessment is "the process of systematically gathering, quantifying, and using the information to determine the instructional effectiveness and the curricular adequacy of a higher education institution (HEI) as a whole (institutional assessment) or its educational programs (program assessment)" [2] (p. 29).

We used the term Information and Communication Technology (ICT) in our Systematic Literature Review (SLR), but the original definition does not completely satisfy the goal of this study [4]. Herein we limit our definition according to the aim and scope of the study. ICTs include Information Systems (IS), Databases, Portals, and Knowledge Management Systems (KMS).

Data is categorized by region based on the continent due to following reasons. 1) Countries are influenced by their neighbours, continent, regional communities, organizations, protocols, and treaties. These groups exist regardless of politics, economy, and education. 2) The analyzed data also supports the above argument that the geographical location affects research on education.

This study finds that a higher utilization of ICTs for Quality Assurance and Accreditation (QAA) has a positive impact, aiding universities and QAA organizations in improving both the ease of providing educational services and the quality of education. Thus, utilization of ICTs allows universities and QAA organizations to better meet the needs of society. Additionally, ICTs enable agencies to fulfil their missions while simultaneously maximizing their resources (time, money, effort...).

Furthermore, we conducted a preliminary case study on a developing country, Afghanistan. The case study suggests conceptual solutions to current state of QAA in Afghanistan, but the solutions have yet to be implemented.

Figure 1 overviews of QAA agencies operational processes and their interactions with key stakeholders.

\section{Background}

The emergence of the digital era and ICTs has significantly impacted society and influenced HE. Consequently, QAA agencies around the world have utilized ICTs for QAA purposes. Additionally, governments, universities, QA agencies, researchers, ICT companies, and other regional and international organizations have introduced various ICTs.

In the past few decades, ICTs have been utilized in HE for QA on an enormous scale. Oliver [5] highlighted the impact of ICTs on contemporary HE and explored potential future developments. His paper discussed the role of ICTs in transforming teaching and learning, and explored how ICTs impact future programs offered by universities and colleges.

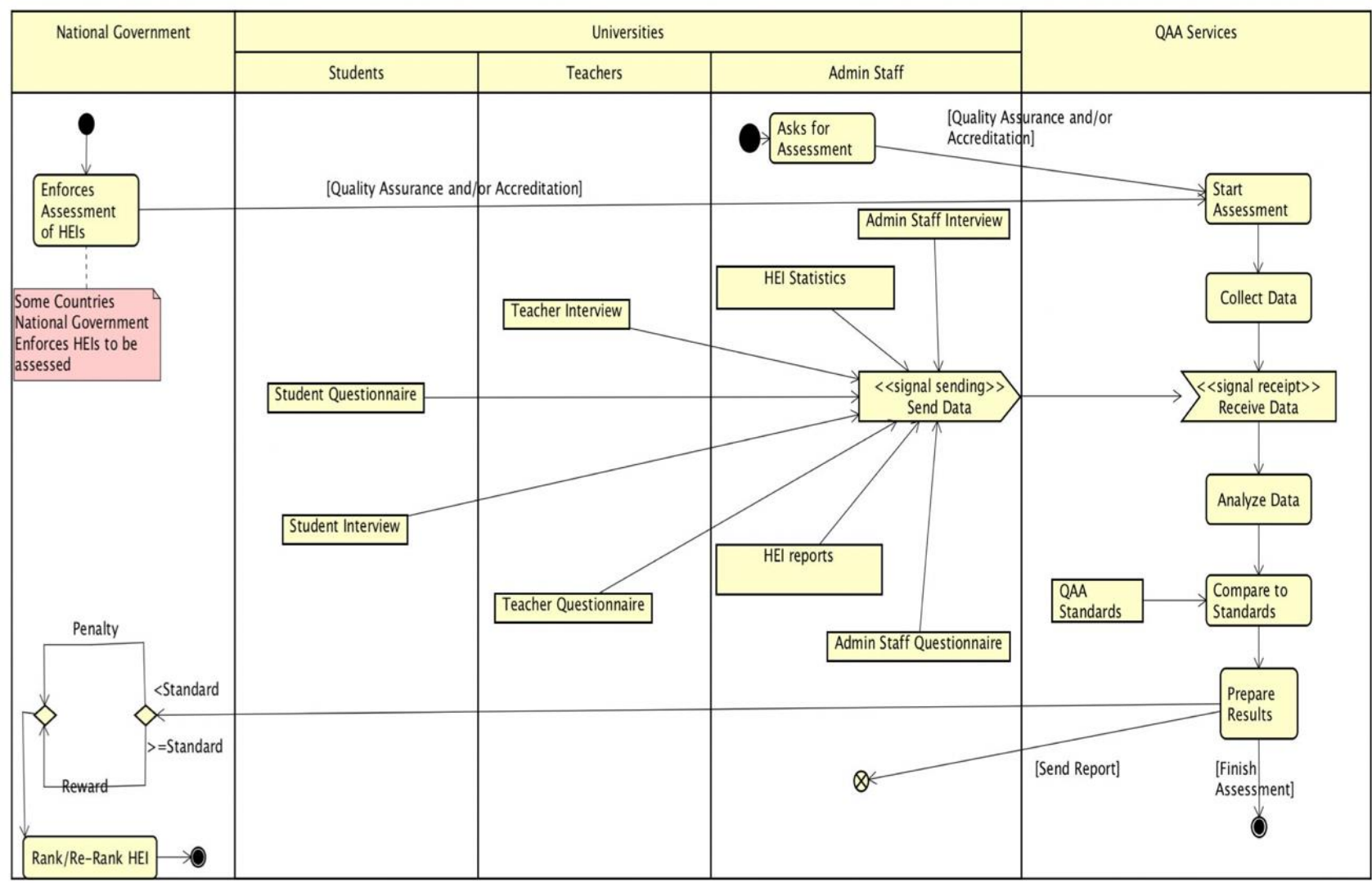

Figure 1. Overview of QAA 
Nadira Banu Kamal et al. [6] mainly discussed the role of ICTs in online teaching and learning tools. Their study compiled the role of ICTs in QAA of HE in general. However, neither of these works focused on the utilization of ICTs in QAA agencies or the QAA unit of HEIs.

\section{Methodology}

The goal of this SLR is to determine how ICTs are utilized for QA and accreditation purposes in the HE sector. We began our SLR by specifying the scope and searching only for documents in the domain of $\mathrm{HE}$ that discuss issues related to QAA supported by ICTs. Topics focusing on online, distance learning, and learning tools and systems are excluded. The lack of information regarding QAA agencies utilizing ICTs in previous research is a limitation of this SLR. Herein we try to follow the approaches of similar surveys such as [3], [7], [8], [9] and [10]. The data is organized based on geography (continents) and key attributes of QAA. This is the body text with no indent. This is the body text with no indent. This is the body text with no indent.

\subsection{SLR Query}

Because an SLR query requires keywords to be identified, we tried to follow the ACM Computing Classification System [11]. However, this was unsuccessful. Most published papers do not support this system or any other rules for determining keywords. It is note-worthy that we wrote several queries combining different keywords, which aligned most closely with the scope and goal of our SLR. We compared the results of these queries prior to determining the final query for this study. In June 2016, we executed an SLR query on titles, abstracts, and keywords of all research papers indexed by Scopus regardless of the publication date and subject area. The initial result was stored as an online list in the first author's Scopus account.

Our query string was configured as:

(("higher education" OR "university") AND ("quality assurance" OR "qaa") AND ("information system" OR (("higher education" OR "university") AND ("quality assurance" OR "qaa") AND ("information system" OR "information technology" OR "database" OR "ict" OR "knowledge management" OR "portal" OR "MIS"))

We found 695 documents. Next, we applied inclusion and exclusion criteria upon reviewing the titles and abstracts. This reduced the number of documents for a full review to 35. We also performed snowballing and identified 16 new relevant documents, some of which were not indexed by Scopus. However, we simply searched Google.com by the paper's title and acquired them from other databases. We verified that the intended paper was returned using the author name(s), publication date, and publisher. In all, 51 documents were considered. After the initial quality assessment and crosschecking with the inclusion and exclusion criteria, 21 documents [12] - [32] were selected for a full review. Figure 2 depicts the paper selection process.

\subsection{Inclusion and Exclusion Criteria}

(i) Inclusion criteria:

a. Documents must be in the domain of HE.

b. Documents must target the role of ICTs in QAA explicitly or implicitly.

(ii) Exclusion criteria:

a. Remove non-English documents.

b. Remove documents that do not discuss QA in HE.

c. Remove the documents that do not present/suggest a conceptual or practical implementation of MIS/Database/Portal/KMS to support QAA in HE.

d. Remove documents discussing the role of ICT in QAA of $\mathrm{HE}$ regarding online/distance education.

e. Remove documents that discuss the role of ICT focusing on teaching or learning tools and methods only (and not the QA aspect). Example: Using pads and smartphones or simulation software for physics and chemistry. 


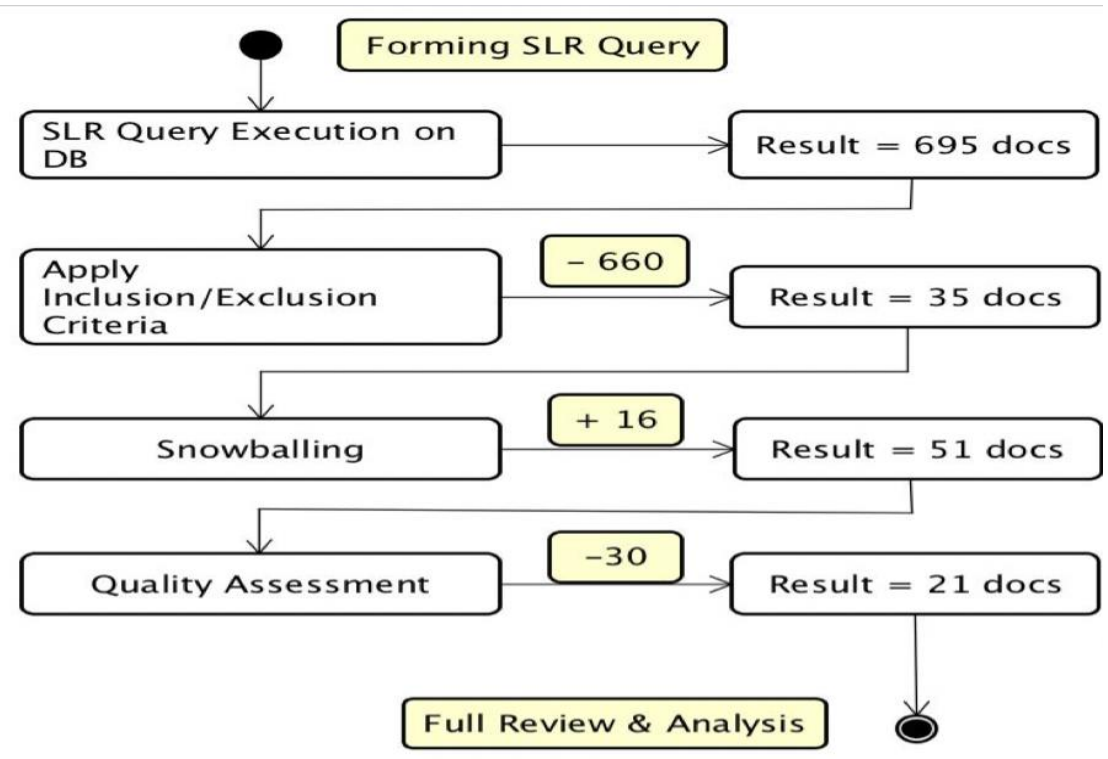

Figure 2. Paper selection process

\subsection{Research Questions}

The goal is to determine the contribution of ICTs in QAA of HE. Here we address fundamental and essential questions.

RQ1: Which continents utilize ICTs for QAAs of HE?

RQ2: Which QAA standards support ICT utilization?

RQ3: What are the key attributes of QAA agencies and HEIs that use ICTs and what are the characteristics of the utilized ICTs?

RQ1 should help elucidate the contribution of ICTs to QAA of HE and understand their influence and diffusion by continent. RQ 2 is essential to recognize the most efficient, applicable, and adaptable QAA standards since various standards exist. This question should be the most beneficial to QAA agencies. RQ3 should identify the characteristics of utilized ICTs, which will be helpful in understanding what type of ICTs are attractive for QAA agencies.

\subsection{Data Extraction Form}

Table 1 illustrates and defines the data extraction form and its aspects. The following parameters are used:

Table 1. Data Extraction Form

\begin{tabular}{ll}
\hline Aspect & Attribute \\
\hline $\begin{array}{l}\text { Abstract } \\
\text { Year \& Source } \\
\text { Location }\end{array}$ & \\
Experiment Design & Continent (Derived from country) \\
QAA standards/guidelines & Types(Conceptual, Practical) \\
HE assessment & Type (Internal, External) \\
approaches & L Type (IS, KM, Portal...) \\
Utilized ICTs & Technology (Programming languages, Database...) \\
& Quality attributes \\
& $\begin{array}{l}\text { Target Processes/Operations (QA, Accreditation, } \\
\text { Both) } \\
\text { Aspect of QA and Accreditation (Higher Education } \\
\text { Institution, Higher Education Program, Both) }\end{array}$ \\
\hline
\end{tabular}


(i) Location: This attribute is used as an indicator of the geographical area where the research was conducted. We used the country name to categorize into continents.

(ii) Experiment Design: This attribute defines the type experiment conducted. Papers are divided into two categories: conceptual (Model, Framework or Has No Tool) and practical (Applied, Implemented or Has Tool). Conceptual experiments do not involve tools or ongoing tool development, whereas practical experiments involve implementation.

(iii) QAA Standards/Guidelines: This attribute indicates the QAA standards or guidelines being followed. These include standards of the local government, local non-government, international QAA agency, or QA unit of HEI.

(iv) Higher Education Assessment: This attribute indicates whether the evaluation method of $\mathrm{HE}$ is conducted by the HEI itself or an outside organization such as a government or other national or international QAA agency.

(v) Utilized ICTs: This attribute includes the type of ICT (e.g., IS, KM, and Portals), its aim (e.g., QA, Accreditation, or another purpose) and the quality attributes addressed.

\subsection{Extracted Models}

We extracted models such as conceptual models, object diagrams, and use case diagrams from the 21 selected papers (Figs. 3 and 4).

\section{Conceptual Model}

Figure 3 is a conceptual model, which depicts the basic concepts involved in the QAA process and the relationship among key stakeholders. Boxes in the yellow background are classes, while red boxes are notes to clarify terms and concepts. The background colour denotes the boundaries between different levels of concepts and stakeholders. For example, purple represents HEIs, grey indicates QAA, while green and blue denote sublevels of HEIs.

The purpose of this meta-model is to illustrate the attribute functionality and the relationship among HEIs and QAA agencies. Hence, it is not detailed, and some classes might be missing. 


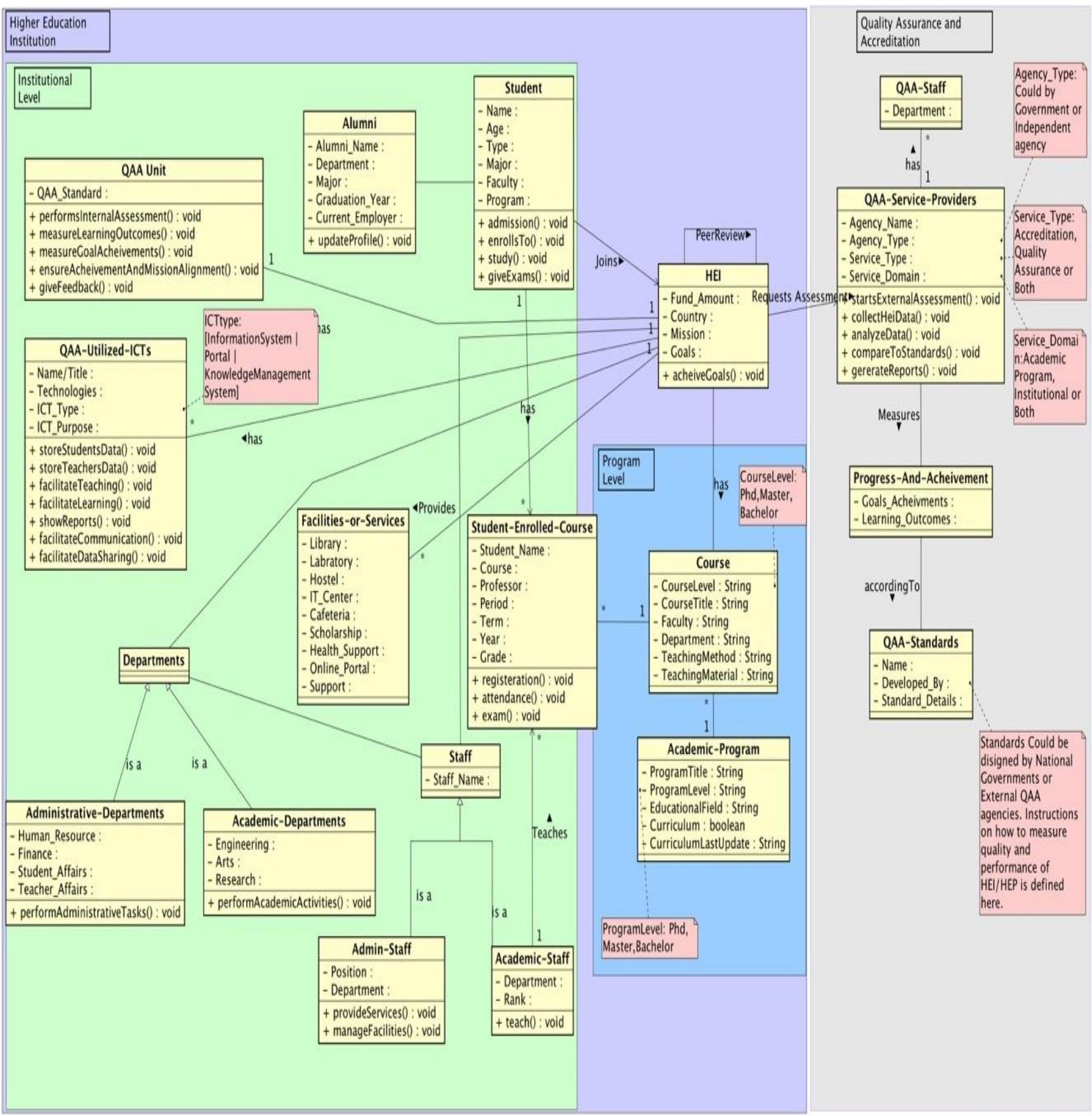

Figure 3. Conceptual model of QAA processes.

\section{Object Diagram}

To verify our conceptual model, Fig. 4 illustrates the object diagram. The data used to trace the object model is not completely real, but the diagram aids in understanding the conceptual model. 


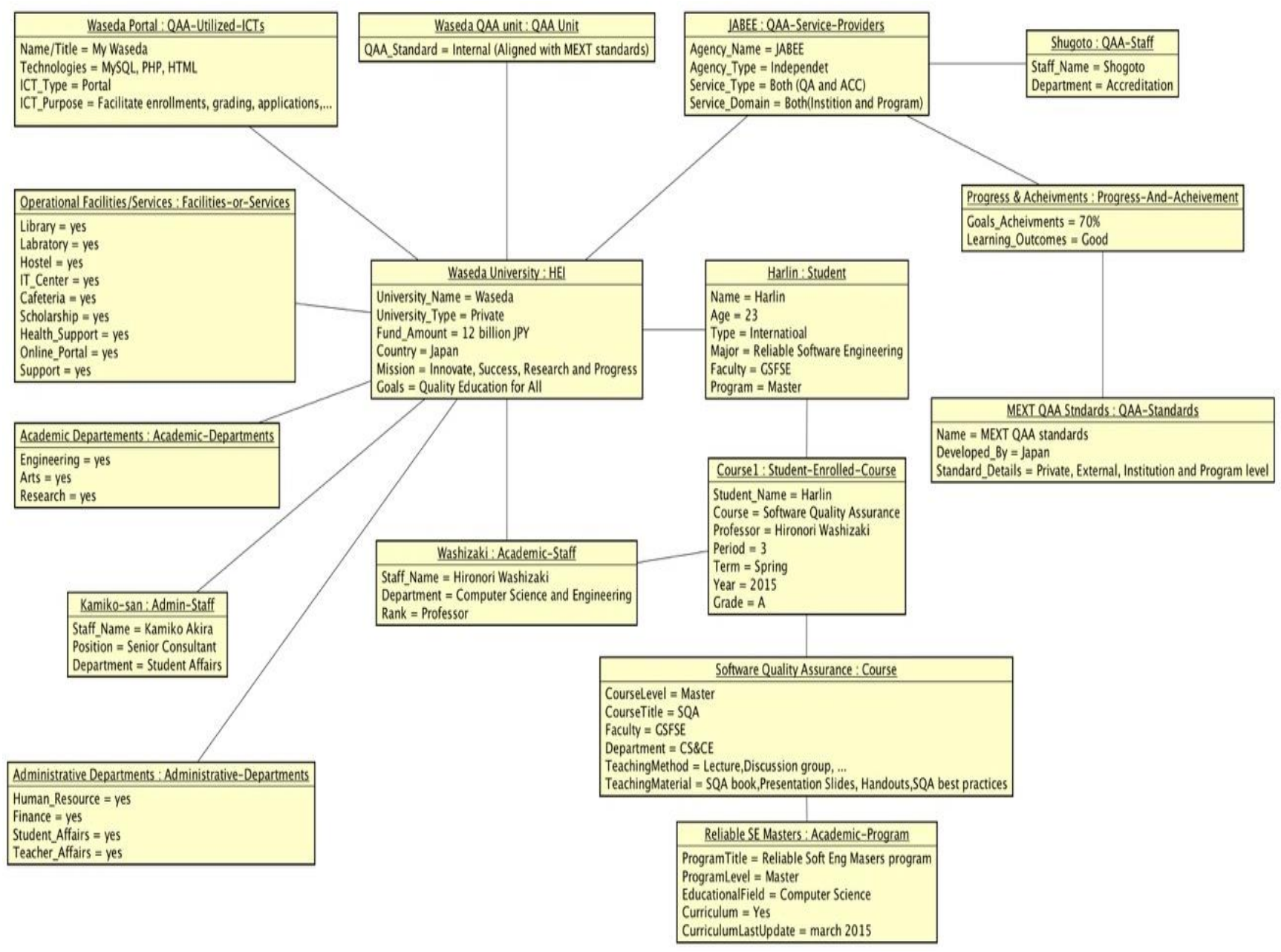

Figure 4. Object diagram for the conceptual model

\section{Analysis Results}

Our analysis was designed to answer the aforementioned research questions. To extract the data and perform the analysis, we used tools such as Atlas.ti for coding and extracting the intended data from the selected studies. We also used Microsoft Excel and the $\mathrm{R}$ software environment to perform basic statistical operations and chart drawings. The findings are summarized below:

\subsection{No ICTs for External QAA}

Table 2 illustrates the categorization of studies based on the assessment type and continent. A very interesting finding is revealed. No research has investigated external assessments.
Table 2. Classification of Data based on Assessment Type and Continent (RQ1)

\begin{tabular}{lllllll}
\hline \multirow{2}{*}{$\begin{array}{l}\text { Assessment } \\
\text { Type }\end{array}$} & \multicolumn{6}{l}{ Continents } \\
\cline { 2 - 7 } & Africa & Asia & Australia & Europe & America & Total \\
\hline Internal & 2 & 2 & 0 & 13 & 0 & 17 \\
External & 0 & 0 & 0 & 0 & 0 & 0 \\
NA & 0 & 2 & 0 & 1 & 1 & 4
\end{tabular}

\subsection{Europe utilized ICTs for QAA the most}

Figure 5 shows that research on the utilization of ICTs for QA began in 2005. Research interest peaked in 2008 and 2009 , but remained stable until 2015 , and is now on the 
decline. Figure 5 and Table 2 highlight two facts. First, ICTs were utilized for QA purposes between 2005 and
2015. Second, ICTs are more often utilized in Europe compared to other continents.

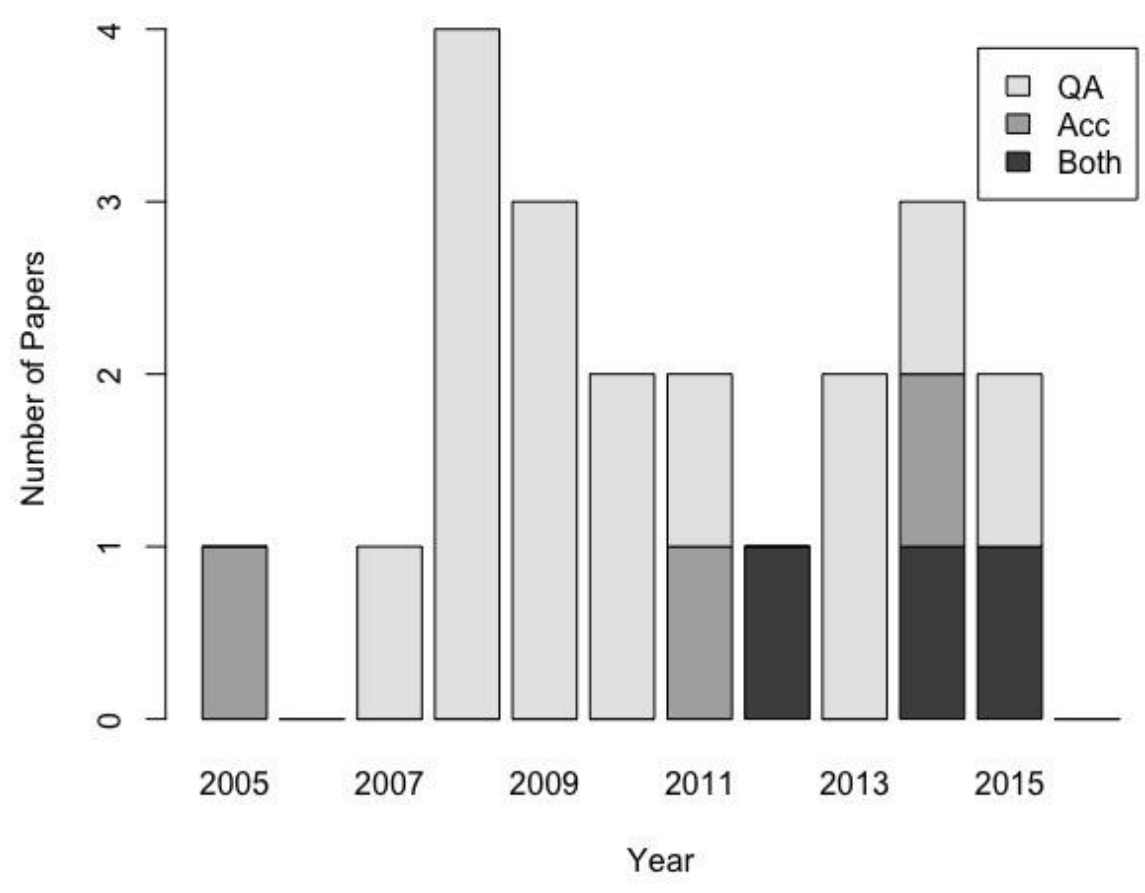

Figure 5. Frequency of published papers

\subsection{More Tools for QA compared to Accreditation}

Table 3 cross-references two important attributes of this SLR. This answers how many studies have practically developed tools and which aspect of HE is targeted. Most studies have focused on developing tools for the QA aspect of HE.

Table 3. Frequency of Studies on tool development and practical experiment design (RQ3)

\begin{tabular}{llll}
\hline Target Aspect of QA & \multicolumn{3}{l}{ Has a tool? } \\
\cline { 2 - 4 } & Yes & No & Total \\
\hline Accreditation & 3 & 0 & 3 \\
QA & 9 & 6 & 15 \\
BOTH & 1 & 2 & 3 \\
Grand Total & 13 & 8 & 21
\end{tabular}

\subsection{European Standard Guidelines (ESG) is a famous QAA standard.}

Table 4 categorizes papers based on the standards used in the study. Some papers employed European standards (e.g., ESG, EHEA), while others were labelled as "European". The same concept has been applied in the "US". Additionally, some employed locally developed standards called "Local". However, some studies did not mention the QA standards and are categorized as "NA". 
Table 4. Frequency of Studies on tool development and practical experiment design (RQ3)

\begin{tabular}{lllll}
\hline Standards & QA & ACC & Both & Total \\
\hline COBIT,ITIL,ISO & 0 & 0 & 1 & 1 \\
European & 4 & 1 & 1 & 6 \\
$\begin{array}{l}\text { European, } \\
\text { ISO }\end{array}$ & 2 & 0 & 0 & 2 \\
European, & 0 & 1 & 0 & 1 \\
US & & & & \\
Local & 4 & 0 & 1 & 5 \\
US & 0 & 1 & 0 & 1 \\
NA & 5 & 0 & 0 & 5 \\
Grand Total & 15 & 3 & 3 & 21 \\
& & & & \\
\hline
\end{tabular}

\subsection{Utilized ICTs technical specifications}

Meanwhile, the most common software systems developed are Knowledge Management Systems, Portals, Information Systems, Decision Support Systems, Models, and Frameworks. The most common programming languages are Java, PHP, VB.bet, Pascal, C++, and Delphi. Databases include Oracle Cloudspace, MySQL, PostgreSQL. The web server is Apache deployed on Linux and Win XP platforms. The latest utilized ICT is cloud technologies. Table 5 shows that distribution of published papers utilizing ICTs considering the program level and the institutional level. The aim is almost balanced. Both HEI and Higher Education Program (HEP) have attracted similar attention from researchers. Only four studies (20\%) focused on both HEI and HEP. Table 6 illustrates the grouping of the approaches based on common topics.
Table 5. Frequency of published papers categorized by the ICT utilization target (RQ3)

\begin{tabular}{ll}
\hline ICTs utilization target & Total \\
\hline Higher Education Program & 8 \\
Higher Education Institutions & 9 \\
Both & 4 \\
Grand Total & 21 \\
\hline
\end{tabular}

Table 6. Utilized ICTs per topic

\begin{tabular}{ll}
\hline Topic & Papers \\
\hline Developed Information & {$[15],[18],[19]$,} \\
Systems for QAA & {$[21],[23],[27]$,} \\
& {$[28],[30],[31]$} \\
Developed KMS for QAA & {$[22],[26],[32]$} \\
$\begin{array}{l}\text { Developed portals for QAA } \\
\text { Conceptual Models, Designs }\end{array}$ & {$[13]$} \\
and Frameworks proposed & {$[12],[14],[16],[20],[24]$,} \\
for QAA & {$[25],[29]$} \\
\hline
\end{tabular}

\subsection{Utilized ICTs and quality attributes}

According to the descriptions of the utilized ICTs, we extracted the quality attributes addressed compared to those mentioned in ISO/IEC 25010 System/Software Product Quality (Table 7). Studies proposing conceptual solutions are models and frameworks for either ICT or HE services and systems.

Definition of letters used in the Table 7. S=ISO/IEC 25010 Software quality attribute, $\mathrm{N}=$ Non software quality attribute, blank cells $=$ No mention 
Table 7. Utilized ICTs addressing ISO/IEC 25010 system/software and non-software product quality attributes

\begin{tabular}{|c|c|c|c|c|c|c|c|c|}
\hline Study & $\begin{array}{l}\text { Functional } \\
\text { Suitability }\end{array}$ & $\begin{array}{l}\text { Performance } \\
\text { Efficiency }\end{array}$ & Compatibility & Usability & Reliability & Security & Maintainability & Portability \\
\hline [12] & & & & & & $S$ & & \\
\hline [13] & S & & & S & $\mathrm{N}$ & S & $S$ & \\
\hline \multicolumn{9}{|l|}{ [14] } \\
\hline [15] & & & & & & S & S & \\
\hline [16] & & S & & & & & & \\
\hline [17] & S & & & S & & & $S$ & \\
\hline [18] & S & & & S & & & $S$ & \\
\hline [19] & S & & & & & & $S$ & \\
\hline [20] & $\mathrm{N}$ & $\mathrm{N}$ & & $\mathrm{N}$ & $\mathrm{N}$ & & $\mathrm{N}$ & \\
\hline [21] & S & & & S & & S & & \\
\hline [22] & $\mathrm{N}$ & & & $\mathrm{N}$ & & & & \\
\hline [23] & $\mathrm{N}$ & $\mathrm{N}$ & & & & & & \\
\hline [24] & $S$ & & & $S$ & & & & \\
\hline \multicolumn{9}{|l|}{ [25] } \\
\hline [26] & & & & $S$ & & & & \\
\hline [27] & S & S & & S & S & S & S & \\
\hline [28] & $S$ & & & $S$ & & & & \\
\hline [29] & $S$ & & & & & & & \\
\hline [30] & $S$ & & & $S$ & & & & \\
\hline [31] & $S$ & & & $S$ & & & & \\
\hline [32] & $S$ & $\mathrm{~N}$ & & $\mathrm{~S}$ & & $S$ & & \\
\hline
\end{tabular}

Although some studies were based on ISO standards, which one (e.g., ISO/IEC 25010) was not specified. In [12], they adapted several ISO standards, including ISO $38500,2700,22301,31000,12207$, and 25000, to design models focusing on ICT governance and management based on academic models. Meanwhile, [20], [14] were based on ISO/IEC 20000 and ISO 9001:2015, respectively.

Figure 6 illustrates the frequency of the addressed quality attributes according to ISO/IEC 25010. There is a significant gap between the frequencies of those quality attributes. "Functional Suitability" and "Usability" they have the highest frequency. The most common cause is that studies that developed tools described their tools' usability and functionality. However, the attributes of "Compatibility" and "Portability" are not address at all, which is not surprising because these attributes are more technical and specific to software engineering and the main focus of this SLR is QA and HE. 


\section{Frequency of Quality Attributes based on ISO/IEC 25010}

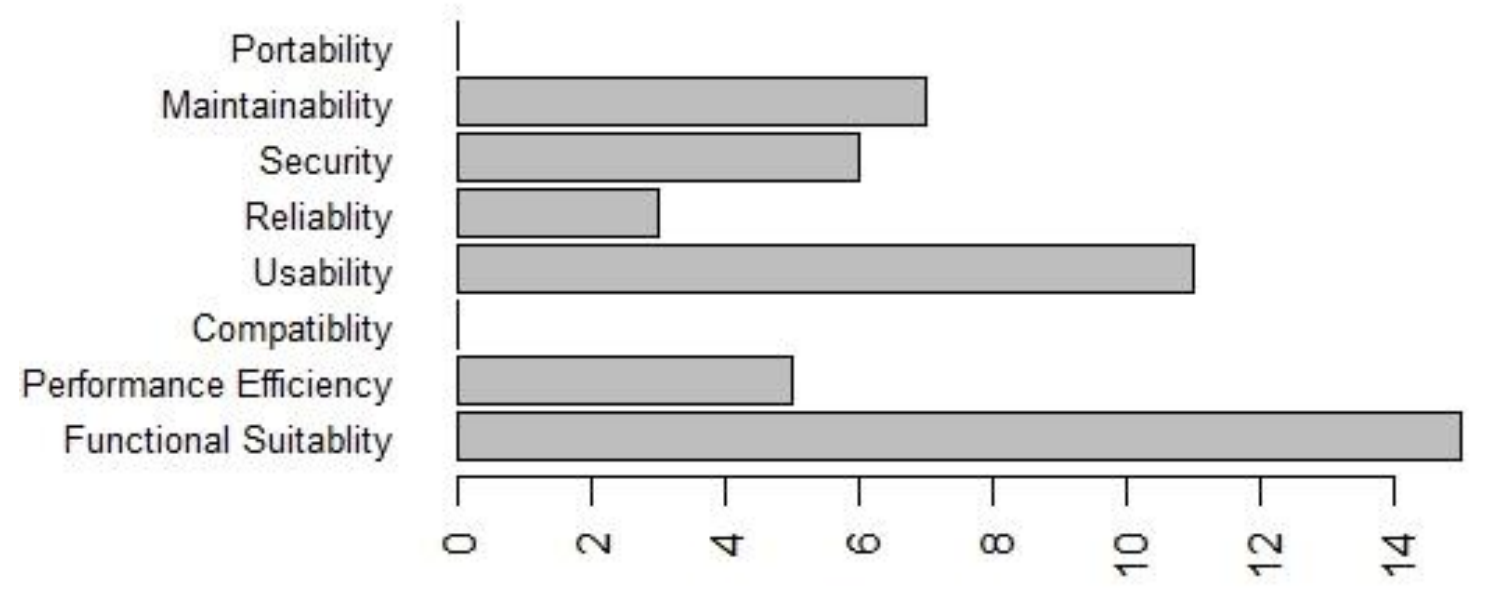

Figure 6. Frequency of mentioned ISO/IEC 25010 quality attributes

Other Quality Attributes

The quality attributes addressed in this section are those listed in the quality model of ISO/IEC 25010.

\section{Threats to Validity}

The analysis was conducted by a single person. It is possible that some information was omitted. Moreover, the analysis is limited by the analytical skills of that single person.

\section{Limitations}

Some limitations include missing classes and diagrams. The quality attributes extracted from the selected papers comply with the ISO/IEC 25010 Software/System quality attributes partially or at a lower level. Some papers mention quality attributes that are not listed in the ISO/IEC 25010, and all columns in Table 7 are blank (i.e., [25] in Table. 7). The lack of addressing ISO/IEC 25010 Software/System quality attributes even implicitly or indirectly is because this SLR mainly focused on QA and $\mathrm{HE}$, not software engineering.

\section{Case Study of a developing country (Afghanistan)}

We decided to develop recommendations for Afghanistan, which is a developing country. Because the author of this thesis is from Afghanistan, he was able to collect data about Afghanistan's Quality Enhancement and Accreditation Directorate (QEAD) of the Ministry of Higher Education (MoHE) by conducting interviews with Afghanistan QAA staff, distributing questionnaires, and collecting raw data such as QEAD guidelines and other materials. Prior to making recommendations, the current QAA status must be understood.

\subsection{Understanding QAA current status in Afghanistan}

The MoHE established QAA in 2011. QEAD of MoHE performs accreditation according to 12 standards that they developed. Currently, QEAD is the only QAA agency in Afghanistan that operates based on the model illustrated in Fig. 7. 


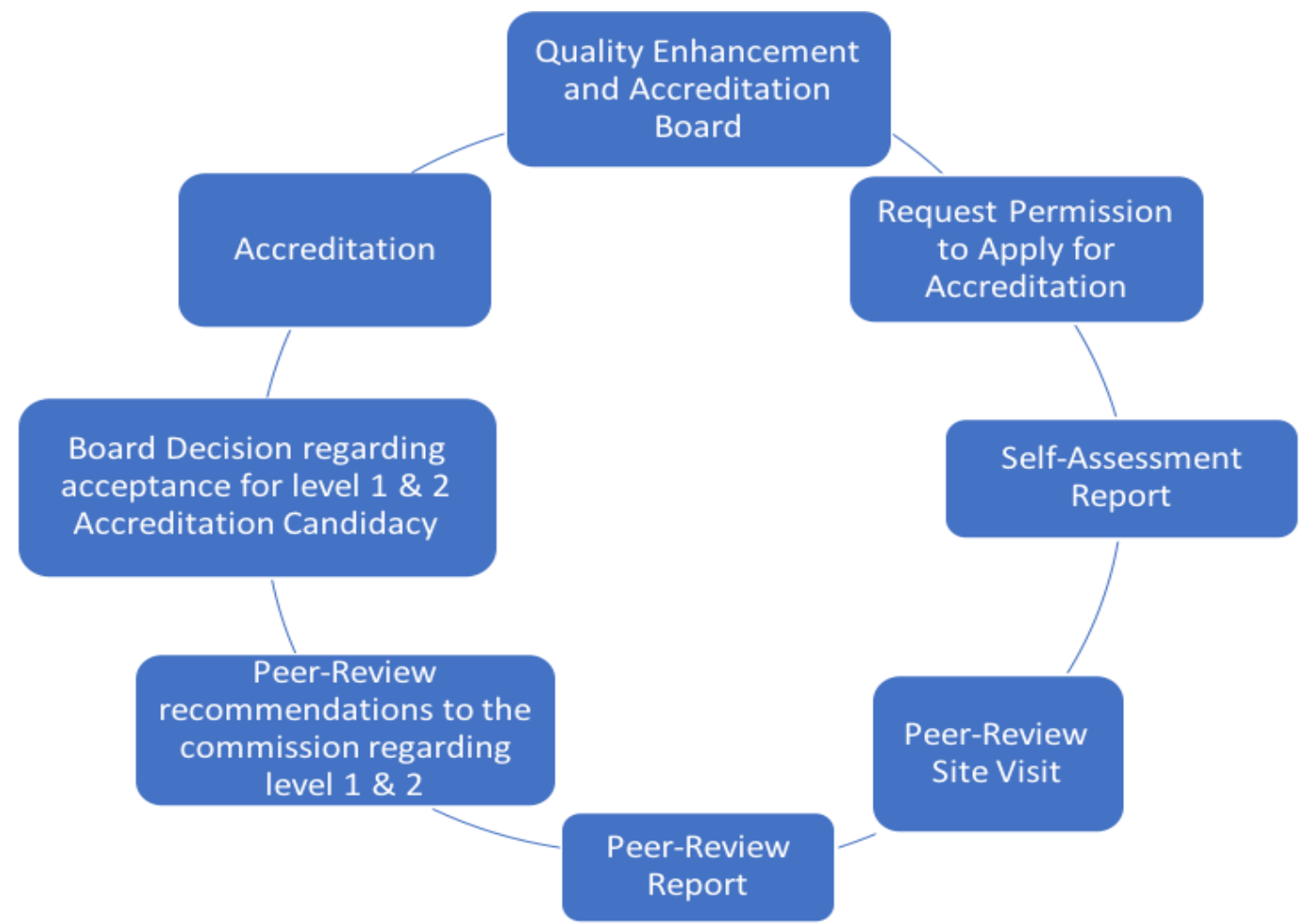

Figure 7. Afghanistan QAA process model

Since QAA processes are new in Afghanistan, two levels of Accreditation are planned to familiarize Universities with the process and to maintain the quality balance of Accreditation. Figure 8 illustrates the Accreditation process and the activities of the stakeholders.

\subsection{Challenges and Limitations in Utilizing ICTs}

This section addresses barriers for QEAD to use advanced and comprehensive ICTs for their internal operations. There are several challenges that QAED is currently facing:

1. Poor Skills of QEAD staff in using software

2. Poor Skills in performing intermediate or advanced analysis

3. No access to tools for better analysis

4. Lack of training for capacity building of QEAD staff
Table 8. Utilized Software in QAED

\begin{tabular}{|c|c|c|c|}
\hline ICT & Location & Purpose & $\begin{array}{l}\text { Usage } \\
\text { Frequency }\end{array}$ \\
\hline $\begin{array}{l}\text { Microsoft } \\
\text { Office } \\
\text { Applications } \\
\text { (Word, } \\
\text { Excel, } \\
\text { PowerPoint) }\end{array}$ & $\begin{array}{l}\text { QAED } \\
\text { staff PC }\end{array}$ & $\begin{array}{l}\text { Writing } \\
\text { Reports, } \\
\text { designing } \\
\text { questionnair } \\
\text { es, Basic } \\
\text { Analysis, } \\
\text { Preparing } \\
\text { Presentation. }\end{array}$ & $\begin{array}{l}\text { Almost } \\
\text { always }\end{array}$ \\
\hline $\begin{array}{l}\text { Video } \\
\text { Conference }\end{array}$ & $\begin{array}{l}\text { QAED } \\
\text { offices }\end{array}$ & $\begin{array}{l}\text { To hold } \\
\text { monthly } \\
\text { meetings } \\
\text { with QEAD } \\
\text { units and } \\
\text { Universities. }\end{array}$ & $\begin{array}{l}\text { Occasionall } \\
\mathrm{y}\end{array}$ \\
\hline
\end{tabular}

\subsection{Utilized ICTs in QEAD of MoHE Afghanistan}

Table 8 illustrates the utilized ICTs in QAED based on a questionnaire completed by the QEAD staff. 


\subsection{Utilized ICTs in Afghanistan HEls (Government and Private)}

Table 9 lists the utilized ICTs in HEIs. The least commonly utilized is Information Systems, while Microsoft Excel is the mostly commonly utilized.

Table 9. Utilized Software in HEls

\begin{tabular}{|c|c|c|}
\hline ICT & Location & Purpose \\
\hline $\begin{array}{l}\text { Microsoft } \\
\text { Office } \\
\text { Applications( } \\
\text { Word, Excel, } \\
\text { PowerPoint) }\end{array}$ & HEI & $\begin{array}{l}\text { Writing Reports, } \\
\text { Analysis, Preparing } \\
\text { Presentations. }\end{array}$ \\
\hline SPSS & HEI & $\begin{array}{l}\text { Analysis, Monitoring } \\
\text { Progress, Reporting }\end{array}$ \\
\hline $\begin{array}{l}\text { Information } \\
\text { System }\end{array}$ & HEI & $\begin{array}{l}\text { Managing Students } \\
\text { and Staff records, } \\
\text { Reporting }\end{array}$ \\
\hline
\end{tabular}

\subsection{Recommendations for Afghanistan QAA}

Our recommendations are on two levels: 1) the HEI level and 2) the QAA level.

(vi) According to ISO and ESG/ENQA standards, QEAD could encourage HEIs to utilize ICTs to manage Students, Teachers, and HEIs' data. This should lead to better management, progress monitoring, information sharing, accessibility, reporting, and strategic planning. It could be achieved by slightly modifying the 6th or 7th QEAD standards.

(vii) At the QAED level, several feasible options are available:

a. Utilize existing free/open source software to satisfy their needs.

b. In-house development of an Information System for QAED by the IT Directorate of MoHE.

c. Outsource projects to local software companies.

d. Purchase licensed software.

\section{Discussion}

It is still unclear how QA organizations utilize ICTs for internal operations or how their internal departments and inter-department operations utilize ICTs.

\subsection{RQ1: Which continents utilize ICTs for HEls or QAA agencies?}

Referring to RQ1, one of the main causes behind the wide utilization of ICTs for QAA is the commitment of European countries to common guidelines.

\subsection{RQ2: Which QAA standards support ICTs utilization?}

Developed and developing countries who are members of regional or global communities utilize more effective QAA standards. Developing countries rely mostly on locally developed standards. We believe that developing countries will undergo the same transitional phases as developed countries. However, developing countries have a big advantage because they can learn from past experiences and have additional support from developed countries. It should be mentioned that the achievements of developed countries at the country and continent level are due to regional and global communities and organizations (e.g., the European Union) facilitating opportunities.

We identified COBIT and ESG standards to utilize the latest ICTs. The key difference in these standards is that ESG gives customer autonomy of ICT utilization for QAA, whereas COBIT has developed complex tools (COBIT 5) to meet standards. COBIT 5 is described in [33]. We speculate that QAA agencies avoid utilizing ICTs due to political reasons, corruption, or monetary constraints.

\subsection{RQ3: What are the key attributes of QAA agencies and HEls that utilize ICTs, and what are the characteristics of utilized ICTs?}

Utilization of ICTs in QAA is influenced by academic developments in countries and continents. We assert that continents employing the most recent technologies design better QAA standards. We discuss this issue by focusing the dimensions of QAA, which accommodate ICTs utilization. Firstly, to accommodate ICT utilization, both program and institutional level assessments are necessary. Experimental designs are practical and mostly supported by a tool. Secondly, utilized ICTs from a technical perspective are mainly for information systems deployed at the HEIs, which is where the data collection process starts. We believe that QAA agencies can add new services according to the available ICTs. 


\subsection{Recommendations based on Systematic Review for a Developing country (Afghanistan)}

We tried to devise recommendations for Afghanistan's QEAD as much as feasibly possible considering our SLR findings. Currently, QEAD encourages ICTs such as Internet accessibility for students and teachers and using MS PowerPoint and projectors in lecture courses. ICTs could be better if next-phase HEIs use software systems for data collection, processing, and storage. Utilizing Information System could help QAED perform tasks, manage data, and track the progress of HEIs, but the QEAD staff or Board members need to be sufficiently skilled to analyze data and compose analytical reports and/or feedback to HEIs.

The process of proposing more feasible and specific recommendations to Afghanistan QAA agency QEAD is still in progress. However, the Capability Maturity Model Integration (CMMI) [36] model may be one of the best option, but it has yet to be practiced by QAA agencies.

\section{Usage}

\subsection{QAA agencies}

Firstly, QAA agencies can use this SLR as a report on the utilization of ICTs in QAA agencies at the continent and global levels. QAA agencies can reassess their goals, policies, and strategies to enhance operation efficiency. They can improve the accuracy and reliability of their decisions at both the strategic and operation levels. Such improvements will conserve resources such as time, money, and human power. Secondly, this SLR indirectly encourages QAA agencies to consider adding new or enhancing existing services according to the more recent ICTs to improve HEIs and HEPs. Such services will result in an improved educational system and better students being delivered to society.

\subsection{Researchers}

This study also acts as a literature review for researchers interested in this topic. It provides a clear picture of the contribution of ICTs in QAA. This should allow researchers to incorporate state of the art technologies for QAA.

\subsection{Afghanistan QAA agency}

Beside the generally proposed usage for QAA agencies, the Afghanistan QAA agency could refer to papers [12][32] to improve the current accreditation process models as well as to adopt more efficient strategies, models, and frameworks supported by ICTs. Since the scope of the results of this study are limited, papers [12]-[32] contain additional useful information.

\section{Conclusion and Future Work}

ICTs are utilized for QA at both QAA agencies and QAA unit of HEIs with the goal of improving assessments of HEIs and HEPs. ICTs are important to collect and process various input data related to students, teachers, HEIs, and HEPs. ICT utilization is more common as an internal assessment performed by the QAA unit of HEIs than external assessments conducted by QAA agencies. Because the QAA units of HEIs are responsible for data collection, they have easy and direct access to stakeholders (HEIs, Students, and Teachers). QAA Standards and HEIs by geographical location are identified as key drivers of efficient ICT utilization in the QAA unit of HEIs. QAA agencies and HEIs in developed countries are utilizing up to date technologies compared to developing countries.

Developing countries could learn and benefit from existing models, frameworks, and standards that have been proven effective. In the future, we plan to elucidate other dimensions of ICT utilization in QAA agencies. We are preparing to survey well-known and globally recognized QAA agencies. And we will be extending our case study by developing a software for QAED of Afghanistan based on current research results and measure the differences which it makes along with its causes.

\section{References}

[1] The Organization for Economic Co-operation and Development https://data.oecd.org/unemp/unemployment-rates-byeducation-level.htm, Online, Accessed on 14th June 2017.

[2] Lazar VLÂSCEANU, Laura GRÜNBERG, and Dan PÂRLEA, Quality Assurance and Accreditation: A Glossary of Basic Terms and Definitions, (2007), http://unesdoc.unesco.org/images/0013/001346/134621e.p df, Accessed on 14th June 2017.

[3] Kitchenham B., Evidence-Based Software Engineering, and Systematic Literature Reviews, (2006) Lecture Notes in Computer Science, vol 4034.

[4] http://searchcio.techtarget.com/definition/ICT-informationand-communications-technology-or-technologies, Online, Accessed on 22 Jan 2017.

[5] Oliver, R., The role of ICT in higher education for the $21 \mathrm{st}$ century: ICT as a change agent for education, (2002) Proceedings of the Higher Education for the 21st Century Conference.

[6] Nadira Banu Kamal, A.R., Thahira Banu, A., ICT in higher education-a study, (2012) Canadian Journal on Data, Information and Knowledge Engineering, 1 (1), pp. 1-12. 
[7] Petersen, K., Vakkalanka, S., Kuzniarz, L.Guidelines for conducting systematic mapping studies in software engineering: An update (2015) Information and Software Technology, 64, pp. 1-18.

[8] Sharafi, Z., Soh, Z., Guéhéneuc, Y.-G, A systematic literature review on the usage of eye-tracking in software engineering, (2015) Information and Software Technology, 67, pp. 79-107.

[9] Quezada-Sarmiento, P.-A., Enciso-Quispe, L.-E., Garbajosa, J., Washizaki, H., Curricular design based in bodies of knowledge: Engineering education for the innovation and the industry, (2016) Proceedings of 2016 SAI Computing Conference, SAI 2016, art. no. 7556077 , pp. 843-849.

[10] Washizaki, H., Guéhéneuc, Y.-G., Khomh, F., A taxonomy for program metamodels in program reverse engineering, (2016) Proceedings - 2016 IEEE International Conference on Software Maintenance and Evolution, ICSME 2016, art. no. 7816453, pp. 44-55.

[11] ACM Computing Classification System, http://dl.acm.org/ccs/ccs_flat.cfm\#10003456, Online, Accessed on 14th July 2016

[12] Montenegro, C.W., Flores, D.A., An integrated model for ICT Governance and Management applied to the Council for Evaluation, Accreditation and Quality Assurance of Higher Education Institutions in Ecuador (CEAACES), (2016) 2015 International Conference on Computing, Communication and Security, ICCCS 2015, art. no. 7374158 .

[13] Terziyan, V., Golovianko, M., Shevchenko, O., Semantic Portal as a Tool for Structural Reform of the Ukrainian Educational System, (2015) Information Technology for Development, 21 (3), pp. 381-402.

[14] Zgodavová, K., Urbančíková, N., Kisela, M., Enhancement of the quality assurance model at the Slovak University: Case study, (2015) Quality Innovation Prosperity, 19 (2), pp. 1-17.

[15] Schreier, U., Reusch, M., Hüffmeyer, M., Belzer, D., Information system support for quality management applying European standards and guidelines for higher education, (2014) CSEDU 2014 - Proceedings of the 6th International Conference on Computer Supported Education, 1, pp. 309-316.

[16] Igbape, E.M., Idogho, P .O., Performance evaluation model for quality assurance in Nigeria higher education, (2014) Lecture Notes in Engineering and Computer Science, 1, pp. 334-343.

[17] Skalka, J., Drlik, M., Svec, P., Knowledge discovery from university information systems for purposes of quality assurance implementation, (2013) IEEE Global Engineering Education Conference, EDUCON, art. no. 6530165, pp. 591-596.

[18] Mijic, D., Jankovic, D., Towards improvement of the study programme quality: Alumni tracking information system, (2012) Advances in Intelligent and Soft Computing, 150 AISC, pp. 291-300.

[19] Chalaris, M., Tsolakidis, A., Sgouropoulou, C., Chalaris, I., Developing an information system for quality assurance in higher education using the balanced scorecard technique - the case study of TEI-A, (2011) Proceedings - 2011 Panhellenic Conference on Informatics, PCI 2011, art. no. 6065117, pp. 373-377.

[20] Lezcano, J.-M., Adachihara, H., Prunier, M., Experimenting design and implementation of an educational services management system based on ISO/IEC 20000 standard, (2010) Communications in Computer and Information Science, 73 CCIS, pp. 55-60.

[21] Hausman, S., Debiec, P., Materka, A., Strzelecki, M., Wiak, S., An innovative internet database system for teaching assignment management and quality assurance at the Technical University of Łódź, (2010) World Transactions on Engineering and Technology Education, 8 (2), pp. 168-174.

[22] Chantarasombat, C., Model a knowledge management for educational quality assurance in faculty of education, Mahasarakham university in Thailand, (2009) European Journal of Social Sciences, 11 (3), pp. 428-440.

[23] Alzoabi, Z., Diko, F., Alnoukari, M., Enhancing education quality assurance using information systems: QAAS system, (2008) Proceedings - International Symposium on Information Technology 2008, ITSim, 1, art. no. 4631579.

[24] Bahzad, Y., Irani, Z., Developing a quality assurance model for small military institutions, (2008) Proceedings of the European and Mediterranean Conference on Information Systems, EMCIS 2008.

[25] Kettunen, J., A conceptual framework to help evaluate the quality of institutional performance,(2008) Quality Assurance in Education, 16 (4), pp. 322-332.

[26] Harkiolakis, N., An automated approach to assessment management of higher education institutions,(2005) EUROCON 2005 - The International Conference on Computer as a Tool, II, art. no. 1630142, pp. 1097-1100.

[27] Pouyioutas, P., Gjermundrod, H., Dionysiou, I., The Pilot use and evaluation of reprotool version 3. 0, (2013) Source of the Document International Conference on Education and New Learning Technologies,

[28] Dosbergs, D., PROCON-A tool for curricula accreditation, (2011) 3rd International Conference on Computer Supported Education, SCITEPRESS

[29] In-Sook, K., Jeong-Woo, Ch., A conceptual model of decision support system for continuous quality improvement of engineering educational program,(2009) Int. Conference on Engineering Education, pp. 11-14

[30] Selmoune, N., Alimazighi, Z., A decisional tool for quality improvement in higher education, (2008) International Conference on Information \& Communication Technologies: From Theory to Applications, IEEE Conference.

[31] Solbjørg, O.K., Søsveen, A., Stokke, B.T., Quality assurance support system in engineering education. Principles and activities, (2008) SEFI 2008 Annual Conference.

[32] Moisil, I., Oprean, C., Lobont, L., Kifor, C., Ciprian, C., EEdU-quality-software tools for quality management in higher education, (2007) 6th International Conference on E-ACTIVITIES

[33] COBIT 5, http://www.isaca.org/Cobit/pages/default.aspx , Online, Accessed on 7th May 2017

[34] Ali Sajjad Haris, Washizaki, H., Fukazawa, Y., Utilization of ICTs in Quality Assurance and Accreditation of Higher Education: Systematic Literature Review,(2017) IEEE TALE

[35] Quality Assurance and Accreditation Guidelines, (2015), Quality Enhancement and Accreditation Directorate of Ministry of Higher Education.

[36] Capability Maturity Model Integration, http://cmmiinstitute.com/capability-maturity-modelintegration, , Online, Accessed on 3rd March 2018 